\title{
Environmental Forensic
}

\section{SAMPLING MICROPLASTICS FOR ENVIRONMENTAL FORENSIC APPLICATIONS}

\author{
Claire Gwinnett ${ }^{1}$, Eleanor Harrison ${ }^{1}$, Amy Osborne ${ }^{1}$, Alberto Pivato ${ }^{2}$ and George Varghese ${ }^{3}$ \\ ${ }^{1}$ Staffordshire University, United Kingdom \\ ${ }^{2}$ University of Padova, Italy \\ ${ }^{3}$ NIT Calicut, Kozhikode, India
}

\section{Microplastics - the new challenge to an environ- mental forensic expert}

Environmental forensics involves the investigation of a diverse range of pollutants that have been accidentally or deliberately released into the environment, to understand their origin and aid the courts in attributing responsibility. For decades, pollutants such as oil and heavy metals, have been the focus of investigation. More recently, emerging pollutants such as plastic waste have become of interest to environmental forensic scientists (Aswini and Varghese, 2020). Plastics have revolutionised our daily lives and have provided significant benefits for many industries; however, although the societal benefits have been immense; there is no doubt that plastic has developed into a considerable environmental problem, resulting in calls for plastics to be classed as a hazardous waste (Rochman et al., 2013a).

The extent of this pollution type is vast; far greater than many other pollutants that are typically investigated by environmental forensic scientists. Only $9 \%$ to $12 \%$ plastic was recycled or incinerated; and $79 \%$ was discharged into the natural environment or landfills (He et al., 2020). Plastic pollution has been found to be present in all of our environmental compartments including atmospheric, terrestrial, marine and freshwater ecosystems. Figure 1 shows the abundant nature of microplastics found on a beach in San Diego. Plastic litter has been found to be present in even the most remote locations on the planet, including the Arctic (Bergmann et al., 2019), and the deep sea (Taylor et al., 2016; Woodall et al., 2014). These plastics pose a problem to aquatic biota in both marine and freshwater environments; mega plastic ( $>1 \mathrm{~m}$ ) and macro plastic items $(2.5 \mathrm{~cm}-1 \mathrm{~m})$ cause entanglement, suffocation and starvation and microplastics ( $<5 \mathrm{~mm}$ ) exposure leads to a reduction in fecundity, reduced ability to remove pathogenic bacteria and lower feeding rates (GESAMP, 2019).

Microplastics are released into our environments through a variety of mechanisms, these include both accidental and deliberate release of plastic waste. Primary sources (those which have been deliberately manufactured at this small size, e.g. microbeads in cosmetic products) and secondary sources (formed from the degradation of

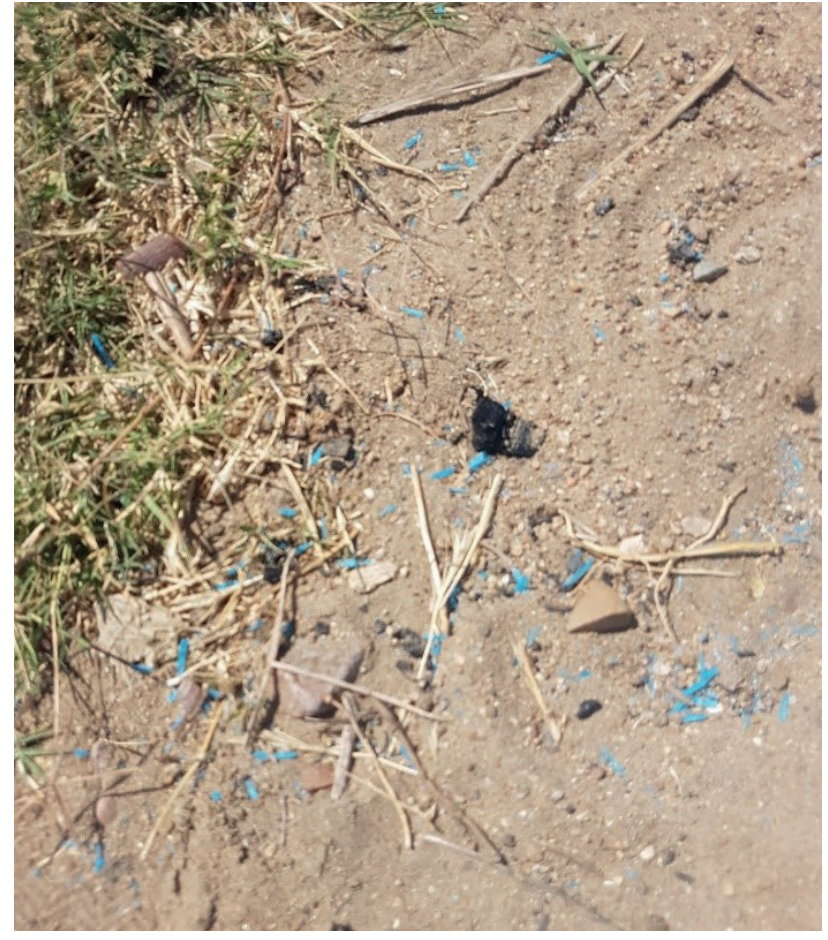

FIGURE 1: Microplastic pollution on San Diego Beach (5-7-18).

larger plastic items) transport between environments easily (Arthur, 2008). For example, synthetic fibres are released into the atmosphere through wear and drying of clothes (O'Brien et al., 2020), into water environments via washing (Fontana, G.D, Mossotti, R and Montarsolo, 2020) and into our terrestrial environments via sewage sludge from wastewater treatment plants (Ren et al., 2020). Although microplastics are not a standard contaminant in the remit of an environmental scientist, with other discipline experts from marine science backgrounds taking the lead in these studies, now it is clear that environmental forensic science approaches are beneficial in understanding the source of such contaminants and also in providing robust methods for sampling. 


\section{Microplastic Sampling}

The microplastic sampling methods used are dependent on the purpose of sampling and the medium being sampled. Air sampling typically uses air pumps which recover particulates onto filter papers, whereby they are easily recovered for analysis. Although air sampling for microplastics is relatively new, it has adopted approaches from other air pollution sampling techniques.

Sampling water is a little more complex depending on the amount of water being sampled, the depth and the microplastic size fraction being targeted. Water sampling can include volume reduction approaches which employs the use of nets with a given mesh size, such as neuston or manta nets that are towed along the surface (Schönlau et al., 2020) or bongo nets for sampling below the surface (Doyle et al., 2011). Alternatively, grab sampling, aka bulk sampling may be employed, where a given amount of water is collected either by using a container, such as a metal bucket (for surface sampling) or niskin bottle (for below surface sampling - Figure 2) or an in-situ pump. Grab sampling is not size selective unlike the use of any mesh or filters which will only capture samples larger than its mesh/ pore size. This typically leads to microplastics smaller than 300 micrometers, (a common mesh size) not being

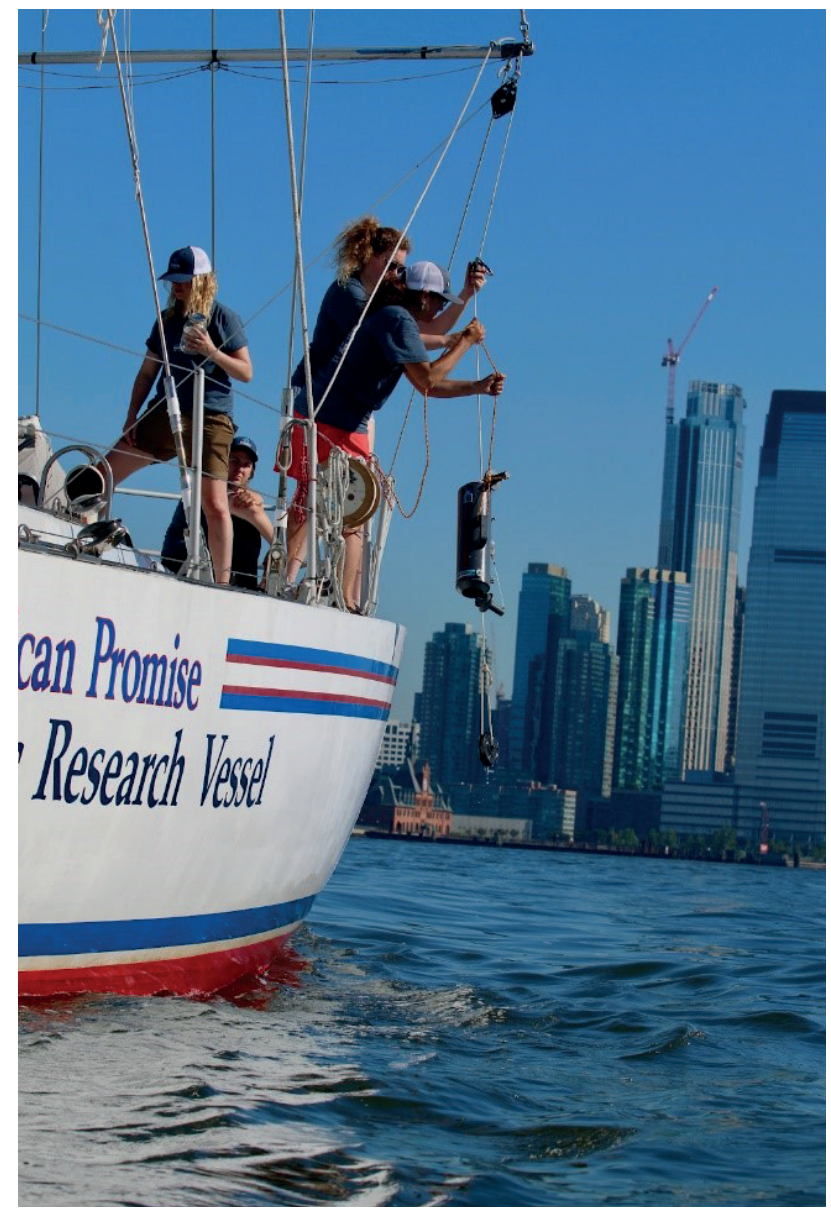

FIGURE 2: Water sampling using a niskin bottle along the Hudson River with Staffordshire University (UK) and the Rozalia Project (USA). Photo courtesy of the Rozalia Project. collected (Setälä, 2016), which is problematic when trying to understand the extent of this pollution. A critique of the different methods employed for sampling water for microplastics was completed by Prata et al.

Soil sampling utilises metal augers or steel soil samplers (usually trowels) to obtain samples to a given depth (Yang et al., 2021). Figure 3a shows a metal auger used for soil sampling. Sampling in beach sediments (Figure 1) is carried out by scraping out a small depth of sediments from a definite area. The procedure specified by NOAA (Lippiatt et al., 2013) for sampling of micro-debris from shoreline is often adopted. Figure $3 \mathrm{~b}$ demonstrates mapping out soil sampling locations along a bank of a river.
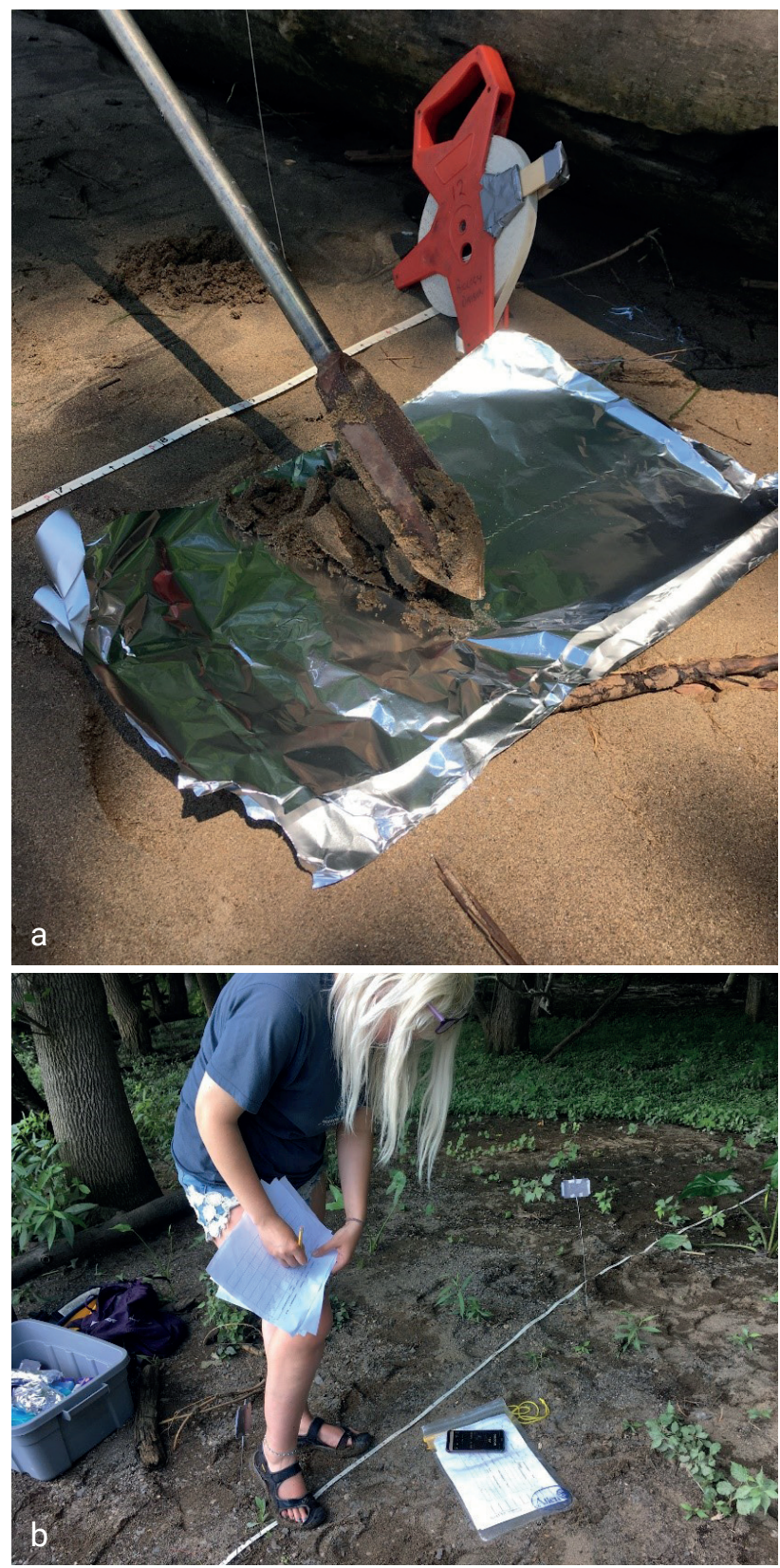

FIGURE 3a-b: Soil Sampling along the Hudson River with Staffordshire University (UK) and Rozalia Project (USA) Photos courtesy of the Rozalia Project. 
A specific strategy should be employed for complex biosolid matrices such as composts, anaerobic digestates and sewage sludges where microplastics are widely found nowadays. These end-of-wastes can be directly used as bio-fertilizers in soils and, therefore, a deep investigation on concentrations of MPs is required to avoid their remission into the biosphere.

Because it is not practicable to separate the MPs and the solid matrix before the sampling phase, the sampling should follow several standards developed specifically for the above cited biosolids. The choice of the approach is determined by the research, technical or forensic question and involves considerations of the hypothesized analyte distribution in the field, potential sources, or final destination.

\section{Microplastic sampling for forensic applications}

Sampling of contaminants for the context of the courts, requires robust procedures. In environmental forensic sampling, the integrity and continuity of the sample is paramount. In microplastic research studies, the requirements of court are not currently present but as we move towards gaining source level information from microplastic samples, the need for methods that can stand up to scrutiny in court is required. Regardless of the sample type, they should be secured for transportation in a manner that prevents contamination and loss. However, for many years, microplastic studies did not consider contamination of samples during sampling, transportation or processing, likely leading to the overestimation of microplastics present. Since then, protocols from the forensic science industry for minimising contamination have been adapted for microplastic use (Woodall et al., 2015).

Environmental forensic procedures require full labelling of samples and detailed descriptions of the locations they have been obtained from. GPS coordinates, along with local details such as proximity to cities, roads and wastewater treatment plants is required yet not always gathered. In addition, control samples from potential sources of the pollutant are not regularly recovered, for example, agricultural plastics that may have entered the soil and subsequently nearby water environments. Collection of controls in other environmental forensic sampling is standard and it is likely due to the infancy of the analysis of this new pollutant that the sub-discipline has not evolved enough to start investigating source in a meaningful manner. For environmental forensic scientists and those investigating waste, inclusion of plastic pollution into workflows is likely to increase in coming years.

\section{REFERENCES}

Arthur. C., Baker. J., Bamford (2008) International Research Workshop on the Occurrence, Effects, and Fate of Microplastic Marine Debris, University of Washington Tacoma, Tacoma, WA. Group
Ashwini S. K. \& George K. Varghese (2020): Environmental forensic analysis of the microplastic pollution at "Nattika" Beach, Kerala Coast, India, Environmental Forensics, DOI: 10.1080/15275922.2019.1693442

Bergmann, M., Mützel, S., Primpke, S., Mine B. Tekman, M. B., Trachsel, J. \& Gerdts, G (2019). White and wonderful? Microplastics prevail in snow from the Alps to the Arctic. Science Advances. 5 (8). pp. eaax1157. Available from: https://advances.sciencemag.org/content/5/8/eaax1157

Doyle, M.J., Watson, W., Bowlin, N.M., Sheavly, S.B (2011)Plastic particles in coastal pelagic ecosystems of the Northeast Pacific ocean, Mar. Environ. Res., 71, pp. 41-52, 10.1016/j.marenvres.2010.10.001

Fontana, G.D, Mossotti, R and Montarsolo, A (2020) Assessment of microplastics release from polyester fabrics: The impact of different washing conditions, Environmental Pollution, Volume 264, https:// doi.org/10.1016/j.envpol.2020.113960.

GESAMP. 2019. "Guidelines for the Monitoring and Assessment of Plastic Litter in the Ocean." GESAMP Reports \& Studies. Vol. 99.

He, D., Zhang, X., Hu, J., 2020. Methods for separating microplastics from complex solid matrices: Comparative analysis. J. Hazard. Mater. 124640. doi:10.1016/j.jhazmat.2020.124640

Lippiatt, S., Opfer, S., and Arthur, C. (2013) Marine debris monitoring and assessment: Recommendations for monitoring debris trends in the marine environment. NOAA Technical Memorandum NOSOR\&R-46. Available at: http://marinedebris.noaa.gov/sites/default/files/Lippiatt_et_al_2013.pdf.

O'Brien, S., Okoffo, E.D., O’Brien, J.W., Ribeiro, F.B., Wang, X., Wright, S.L. Samanipour, S., Rauert, C., Toapanta, T.Y.A., Albarracin, R., Thomas, K.V (2020) Airborne emissions of microplastic fibres from domestic laundry dryers, Science of The Total Environment, Volume 747, https://doi.org/10.1016/j.scitotenv.2020.141175.

Prata, J.C., da Costa, J.P., Duarte, A.C., Rocha-Santos, T (2019) Methods for sampling and detection of microplastics in water and sediment: A critical review, TrAC Trends in Analytical Chemistry, Volume 110.

Ren, X., Sun, Y., Wang, Z., Barceló, D., Wang, Q., Zhang, Z., Zhang, Y (2020) Abundance and characteristics of microplastic in sewage sludge: A case study of Yangling, Shaanxi province, China, Case Studies in Chemical and Environmental Engineering, Volume 2, https://doi.org/10.1016/j.cscee.2020.100050.

Rochman, C.M., Browne, M.A., Halpern, B.S., Hentschel, B.T., Hoh, E., Karapanagioti, H.K., Rios-Mendoza, L.M., Takada, H., Teh, S., Thompson, R.C., (2013) Policy: Classify plastic waste as hazardous. Nature. doi:10.1038/494169a

Schönlau, C., Karlsson, T.M., Rotander, A., Nilsson, H., Engwall, M., Bavel, B.V., Kärrman, A (2020) Microplastics in sea-surface waters surrounding Sweden sampled by manta trawl and in-situ pump, Marine Pollution Bulletin, Volume 153, https://doi.org/10.1016/j. marpolbul.2020.111019

Setälä, O., Magnusson, K., Lehtiniemi, M., Norén.F (2016) Distribution and abundance of surface water microlitter in the Baltic Sea: a comparison of two sampling methods, Mar. Pollut. Bull., 110 (2016), pp. 177-183, 10.1016/j.marpolbul.2016.06.065

Taylor, M., Gwinnett, C., Robinson, L. et al. Plastic microfibre ingestion by deep-sea organisms. Sci Rep 6, 33997 (2016). https://doi. org/10.1038/srep33997

Woodall, L. C. et al. The deep sea is a major sink for microplastic debris Royal Society Open Science 1, doi: 10.1098/rsos.140317 (2014).

Woodall, L.C., Gwinnett, C., Packer, M., Thompson, R.C., Robinson, L.F., Paterson, G.L.J (2015) Using a forensic science approach to minimize environmental contamination and to identify microfibres in marine sediments, Marine Pollution Bulletin, Volume 95, Issue 1, https://doi.org/10.1016/j.marpolbul.2015.04.044.

Yang, J., Li, R., Zhou, Q., Li, L., Li, Y., Tu, C., Zhao, X., Xiong, K., Christie, P., Luo,Y (2021) Abundance and morphology of microplastics in an agricultural soil following long-term repeated application of pig manure, Environmental Pollution, Volume 272, https://doi. org/10.1016/j.envpol.2020.116028. 